Military Technical College

Kobry El-Kobbah,

Cairo, Egypt

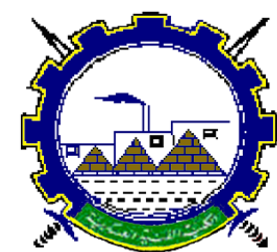

I.C.E.E.2016 $8^{\text {th }}$ International Conference

on

Chemical \& Environmental

Engineering

19-21 April 2016

\title{
EM-2
}

\section{Erosive Burning Modeling for Solid Propellant Rocket Motor}

\author{
Ah. EL-S. Makled*
}

\begin{abstract}
:
Many phenomena occur during Solid Propellant (SP) Rocket Motor (RM) firing, one of the most important is known as SP erosive burning, which occurs at the end of grain, during the earliest period of firing after ignition. Calculating and analyzing erosive burning rate are an essential requirement for evaluating SPRM performance parameters. Intensive theoretical investigations are performed for the prediction of erosive burning and RM internal ballistic parameters. Investigations help in minimizing experimental work, which is expensive, risky and time consuming.
\end{abstract}

This paper presents a SPRM erosive burning computer code with its mathematical simulation, based on heat transfer theory of Lenoir and Robillard. Results of modeling are compared with the results of experimental study and a satisfactory agreement is indicated by an error less than $5 \%$. The experimental work is based on full-scale firing of artillery RM that has higher propellant filling coefficient (volumetric loading).

A comprehensive analysis of the erosive burning phenomena and simplified formula are presented. The presented simulation code can be considered as a powerful tool for design parameters and analysis of the erosive burning rate for SPRM.

Keywords: solid propellant, erosive burning, rocket motor, internal ballistic.

\footnotetext{
${ }^{*}$ Egyptian Armed Forces
} 
Military Technical College

Kobry El-Kobbah,

Cairo, Egypt

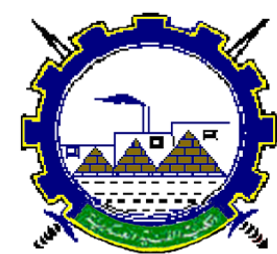

I.C.E.E.2016 $8^{\text {th }}$ International Conference

on

Chemical \& Environmental

Engineering

19 - 21 April 2016

\section{Introduction}

The phenomena of erosive burning is first noted by Mansell after the RM static firing [1, 2], as the burning rate of the SP is less at the forward end than at the nozzle end for internal burning SPRM. In most of the cases, the SPRM designer tends to satisfy higher propellant filling coefficient and steady burning rate at constant operating pressure to minimize insulations and casing thickness of combustion chamber. When erosive burning occurs, the chamber pressure rises over the maximum design pressure increasing the tail-off phase (increasing the dispersion for artillery rockets). Unfortunately; erosive burning can be removed by minimizing the SP filling coefficient (loading factor), a coefficient which needs to be as large as possible especially for artillery rockets and boosting stages. The ability to predict the erosive burning rate of SP is an essential parameter, especially for internal ballistic investigation.

Erosive burning is a very significant phenomenon which occurs with the majority of SP configurations, specially the artillery RM and booster stages. Erosive burning generally occurs when high velocity combustion gases flowing over the SP burning surface is too fast at the end of grain, close to the nozzle part. Erosive burning takes place due to the increase in propellant burning rate, it often occurs with long and narrow effective channel port of SP grain.

Erosive burning seriously affects the performance of SPRM. It occurs primarily in the active port of the grain toward the nozzle; it is more likely to occur when the port passage cross section area $A_{\text {po }}$ is small relative to the nozzle throat area $A_{\text {th }}$ with a port-to-throat area ratio of 4 or less [1].

The SPRM typical pressure (thrust) -time or -time curve includes ignition time, actual burning time and tail-off time. Erosive burning increases the generation of combustion gas that tends to increase the chamber pressure (thrust) during the early phase of the RM firing as shown in Fig. (1).

As soon as the burning enlarges the flow passage, the port gas flow velocity is reduced and erosive burning diminishes until normal burning value is reached along SP grain surface.

Erosive burning occurs in the early burn of the SP grain web, at the nozzle end. It greatly exposes the insulation and aft closure layer thickness due to the effect of hot combustion over a longer period of time (local thermal failure).

\section{Solid Propellant Burning Rate}

The burning rate is defined as the distance traveled by the flame zone per second perpendicular to the SP surface. It is considered one of the vital parameters for SPRM internal ballistics; it is influenced by the combustion chamber operating pressure $\mathrm{P}_{\mathrm{c}}$, the initial 
Military Technical College

Kobry El-Kobbah,

Cairo, Egypt

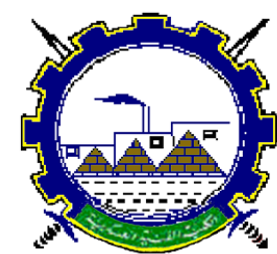

I.C.E.E.2016 $8^{\text {th }}$ International Conference

on

Chemical \& Environmental

Engineering

$19-21$ April 2016

temperature of SP $T_{s p}$, the combustion gas temperature $T_{c}$, the velocity of the combustion gases over the burning surface $v_{\mathrm{g}}$ and even by acceleration and spin of RM during real flight. In the majority of internal ballistic investigation, the simplified relation burning rate $r_{o}$ equation is known as Saint-Robert's law [1]:

$$
r_{o}=a P_{c}^{n} \quad \text { Eq. (1) }
$$

Where $\mathrm{a}$ is the burning rate coefficient depending mainly on $\mathrm{T}_{\mathrm{sp}}, \mathrm{n}$ is the burning rate pressure exponent (combustion index), generally, a and $\mathrm{n}$ are very sensitive constants determined experimentally for each type of SP. Burning rates ranging from 0.25 to $25 \mathrm{~mm} / \mathrm{sec}$ can be obtained, the higher values can be achieved with high pressure and energetic materials $[1,2]$.

From investigation of equation (1), it can be realized that burning rate is very sensitive to the exponent $\mathrm{n}$, high values of $\mathrm{n}$ gives a rapid change of burning rate with pressure, the production technology of SP realizes a combustion index ranging between 0.2 and $0.75[1,2]$. However, at certain gas flow conditions, the erosive burning can seriously affect the performance of SPRM. Erosive burning always refers to the increase in the propellant burning rate caused by the high velocity combustion gases $v_{\mathrm{g}}$ flowing over the propellant surface especially at end segment of SP toward the nozzle.

A relatively simple equation for erosive burning was first developed in 1956 by Lenoir and Robillard (L-R) [1, 2], based on the heat transfer from combustion gases stream to the SP burning surface with the following assumptions [2]:

- Neglecting the unsteady ignition phase, the combustion begins after SP surface receives the amount of heat required for propagation burning;

- the main heat source is thinner flame zone at millimetre over SP burning surface, this thickness is dependent on $\mathrm{P}_{\mathrm{c}}$ and independent of the mass flux of combustion gases;

- the secondary heat source is from combustion stream by convection to SP surface;

- the mass flow rate generated by combustion just only from SP burning surface.

L-R equation comprises two burn rates, $r_{o}$ is the burning rate without erosion, which is mainly a function of $P_{c}$ and $T_{s p}$ as Eq. (1) and erosive burn term $r_{e}$ is the increasing in burning rate due to gas velocity (erosion effects).

Threshold velocity $v_{t h}$ is a value at which if the velocity of burning gases exceeds this value, erosive burning will occurs. When the design pressure of the RM is increased, the value of threshold velocity decreases. A simplified essential form of the SP burning rate can be written as $[2,3,6]$ : 
Military Technical College

Kobry El-Kobbah,

Cairo, Egypt

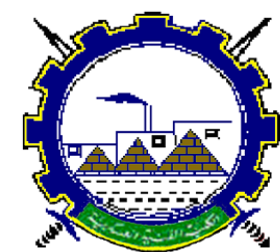

I.C.E.E.2016 $8^{\text {th }}$ International Conference

on

Chemical \& Environmental

Engineering

$19-21$ April 2016

$$
\begin{gathered}
r_{s p}=r_{o}\left(v_{g}<\text { threshold velocity }\right)+r_{e}\left(v_{g} \geq \text { threshold velocity }\right) \\
=r_{o} \text { fun }\left(P_{c}, T_{s p}\right)+r_{e} \text { fun }\left(T_{c}, O / F, v_{g}, \text { propellant ingradient and grain geometry }\right) \\
r_{s p}=\mathrm{aP}_{\mathrm{c}}^{\mathrm{n}}+\alpha_{e b}\left(\dot{m}_{g} / A_{p o}\right)^{0.8} L_{s p}^{-0.2} \exp \left(-\beta r_{s p} \rho_{s p} A_{p o} / \dot{m}_{g}\right) \\
v_{\mathrm{th}}=R T_{c}\left[\frac{182.8}{P_{c}}+(15.4) 10^{-5}\right]
\end{gathered}
$$

Where $\alpha_{\mathrm{eb}}$ is the erosive burning coefficient, $\beta$ is the erosive burning pressure coefficient, $\dot{m}_{g}$ is the mass flow rate of combustion gases, $A_{p o}$ is the SP port area, $\rho_{s p}$ is the SP density and $L_{s p}$ is the initial SP grain length.

\section{Erosive Burning Modeling}

One of the most difficult internal ballistic parameters to evaluate is the burning rate of the SP charge. This parameter must be a function of grain length and firing duration, to determine the accurate performance and combustion characteristics during firing time.

The ability of internal ballistic model to predict the SPRM performance is based on the critical data obtained from the erosive burning model. Erosive burning must be evaluated during quasi-steady state phase. A simplified mathematical model is introduced here to predict the erosive burning versus time. Model is based on R-L Eq. (2), fundamental gas dynamic and thermodynamic relations. Analysis is based on one-dimensional frictionless compressible flow theory.

Equilibrium operating pressure, which is an essential parameter obtained by iteration that balances the continuity equation as $[4,5]$.

$$
\dot{m}_{d i s}=\dot{m}_{g e n}-\frac{d}{d t}\left(\rho_{c} V_{c}\right)
$$

Where $\rho_{c}$ is the combustion gas density, $V_{c}$ is the gaseous volume of combustion chamber, $\dot{m}_{d i s}$ is discharge mass flow rate through nozzle, $\dot{m}_{g e n}$ is generated mass flow rate from burning surface.

The modeling is based on dividing the SP grain axially into a three number of sections (head end, nozzle end and medial section). For each segment, the governing equations are solved by using an iterative technique. Finally a comparison of total amount of $\dot{m}_{g e n}$ from SP is theoretically estimated through the nozzle throat area $\dot{m}_{d i s}$ as Eq. (3).

The SP surface regression rates are assumed to be linear along the SP grain length. The burning rates are separately calculated at the head and nozzle ends, taking into account the erosive burning effect. 
Military Technical College

Kobry El-Kobbah,

Cairo, Egypt

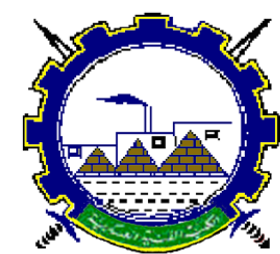

I.C.E.E.2016 $8^{\text {th }}$ International Conference

on

Chemical \& Environmental

Engineering

$19-21$ April 2016

Prediction of the erosive burning, regression rate and other parameters variation with the burning depth $\mathrm{y}+\Delta \mathrm{y}$ is performed by numerical solution as using the following steps.

Quasi Steady State operation: for $\mathrm{y} \neq 0$ the following procedure as adapted for the calculation of the parameters at $\mathrm{y}+\Delta \mathrm{y}$ :

1. Compute the Mach number at nozzle end section $M_{n}$ (usually less than 1) by iteration as:

2 .

$$
M_{n}=\frac{A_{t h}}{A_{p o(n)}}\left(\frac{2}{\gamma+1}\left(1+\frac{\gamma-1}{2} M_{n}^{2}\right)\right)^{\frac{\gamma+1}{2(\gamma-1)}}
$$

The first estimated value is $\mathrm{M}_{\mathrm{n}}=0.85$. The solution is accepted when the difference between two successive values becomes less than 0.002; as $\mid M_{n}($ old $)-M_{n}($ new $) \mid<0.002$

3. Compute the absolute velocity of chamber gases at nozzle end $V_{\mathrm{g}(\mathrm{n})}$

$$
V_{g(n)}=a_{n} M_{n}=\sqrt{\gamma R T_{n}} M_{n}=\sqrt{\gamma} C^{*} \Gamma M_{n}\left(1+\frac{\gamma-1}{2} M_{n}^{2}\right)^{-\frac{1}{2}}
$$

4. Predict the stagnation pressure $\mathrm{P}_{\text {on }}$ and the mass discharge rate $\dot{m}_{d i s}$ as:

$$
\dot{m}_{d i s}=\frac{A_{t h} P_{o n}}{C_{t h}^{*}}=\frac{A_{t h} P_{o n} \Gamma}{\sqrt{R T_{c}}}
$$

The first estimation of $\mathrm{P}_{\text {on }}$ is taken equal to the previous value at $\mathrm{y}$,

5. Compute the pressures at nozzle and head ends $\mathrm{P}_{\mathrm{n}}, \mathrm{P}_{\mathrm{h}}$ from the following equations respectively,

$$
\begin{aligned}
& \frac{P_{n}}{P_{o n}}=\left(1+\frac{\gamma-1}{2} M_{n}^{2}\right)^{\frac{-\gamma}{\gamma-1}} \\
& P_{h}=P_{n}+\frac{\dot{m}_{d i s} v_{g(n)}}{\bar{A}_{p o}}
\end{aligned}
$$

6. Compute the burning rates at head and nozzle ends $r_{h}, r_{n}$ from Eq. (1) and Eq. (2) respectively. The equation of burning rate at nozzle end (Eq. 2) is solved by using Newton-Raphson method. The initial estimate value of $r_{n}$ is taken equal to $r_{h}$. The solution is accepted when the difference between two successive values becomes less or equal to 0.0005 as $\left(\mathrm{X}(\right.$ new $)=\mathrm{X}($ old $\left.)-\mathrm{f}(\mathrm{x}) / \mathrm{f}^{\prime}(\mathrm{x})\right)$ until $\mid r_{n}($ old $)-r_{n}($ new $) \mid \leq 0.00005$

7. Calculate the mass flow generated from burning surface $\dot{m}_{g e n}$ as:

$$
\dot{m}_{g e n}=\rho_{s p}\left(\frac{r_{n}+r_{h}}{2}\right) \bar{A}_{b u}
$$

8. Calculate the change of chamber pressure with depth of burning variation $\mathrm{dP} / \mathrm{dy}$ as: 
Military Technical College

Kobry El-Kobbah,

Cairo, Egypt

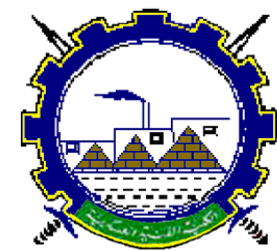

I.C.E.E.2016 $8^{\text {th }}$ International Conference

on

Chemical \& Environmental

Engineering

$19-21$ April 2016

$$
\frac{d P}{d y}=\frac{P_{a v}}{r_{a v}} \frac{\Delta r_{a v}}{\Delta y}+\frac{P_{a v}}{A_{a v}} \frac{\Delta A_{b u}}{\Delta y}
$$

Where $\Delta \mathrm{A}_{\mathrm{b}}, \Delta \mathrm{r}_{\mathrm{av}}$ are the changes in the burning surface area and the average burning rate during the incremental distance burned $\Delta y$ respectively.

9. Perform the mass balance equation to correct the value of $\mathrm{P}_{\text {on }}$ as:

$$
\dot{m}_{d i s}=\dot{m}_{g e n}-\frac{\bar{r}_{s p}}{\Gamma^{2} C_{t h}^{* 2}}\left(\bar{P}_{c} \bar{A}_{b u}+V_{c} \frac{d P}{d y}\right)
$$

Where $V_{c}=V_{c(i)}+\sum \Delta y_{(j)} \bar{A}_{b u(j)}, \mathrm{V}_{\mathrm{ci}}$ is the initial volume of the combustion chamber.

If the mass balance equation $\left(\dot{m}_{D i s} \approx \dot{m}_{g e n}\right)$ is not satisfied, the $\dot{m}_{D i s}$ is updated by using the Eq. (11). A new value of stagnation pressure $\mathrm{P}_{\text {on }}$ is then computed from Eq. (6).

10. Repeat step 3 to 8 until the difference between the two sides of Eq. (11). Is less than 0.0002 . In this case the solution is considered satisfactory.

Initial State operation: at $y=0$, at the beginning of computation the above procedure is respected except that:

In step 3, the first prediction of stagnation pressure is obtained from:

$$
P_{o n}=\left(a \rho_{s p} C_{t h}^{*} A_{b u} / A_{t h}\right)^{\frac{1}{1-n}}\left(1+\frac{\Gamma^{2} A_{t h}^{2}}{2 A_{p o}^{2}}\right)^{\frac{n}{1-n}}
$$

In step 7, it is assumed that $\mathrm{dp} / \mathrm{dy}=0$

Exhaust operation: during tail-off period, the burning surface and $\mathrm{dP} / \mathrm{dy}$ are decreased sharply. In first regime, the mass produced by combustion still exist. In second regime, after the burning is completed and the remainder of combustion gases is simply exhausting out of the nozzle.

First regime: assumed $\mathrm{P}_{\mathrm{h}}=\mathrm{P}_{\mathrm{n}}=\mathrm{P}_{\text {on }}$ and $\mathrm{r}_{\mathrm{n}}=\mathrm{r}_{\mathrm{h}}$

In step 3 first estimate of pressure is obtained from [2]:

$$
P_{o n}=\left(a \rho_{s p} C^{*} \frac{A_{b u}}{A_{c r}}\right)^{1 / 1-n}
$$

In step 7the value of $\mathrm{dP} / \mathrm{dy}$ is obtained from:

$$
\frac{d P}{d y}=\frac{P_{o n}}{(1-n) \bar{A}_{b u}} \frac{\Delta A_{b u}}{\Delta y}
$$

In step 8 the new value of the stagnation pressure for next iteration is obtained from:

$$
P_{o n}(\text { new })=P_{o n}(\text { old })+\frac{d P}{d y} \Delta y
$$

Second regime: assumed $\mathrm{A}_{\mathrm{bu}}=0$ 
Military Technical College

Kobry El-Kobbah,

Cairo, Egypt

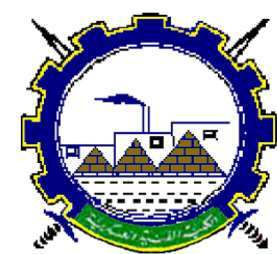

I.C.E.E.2016 $8^{\text {th }}$ International Conference

on

Chemical \& Environmental

Engineering

$19-21$ April 2016

The pressure is computed from [2]:

$$
P_{o n}=P_{s} \exp \left(-\Gamma^{2} C^{*} A_{c r}\left(t-t_{s}\right) / V_{c f}\right)
$$

Where $t$ is the instantaneous time of calculation, $t_{s}$ is the time at the end of calculation, $P_{s}$ is pressure at the end of first tail-off part and $\mathrm{V}_{\mathrm{cf}}$ is the final chamber volume.

\section{Experimental Analysis}

The direct goal of the experimental work is to check the validity of the erosive burning rate mathematical model in case of SP. Through the last decades, very significant experimental work progress is achieved in all areas covering the SPRM design and technology. Availability of the simulation software gave the SPRM designers and analysts a capability that can avoid experimental work. Burning rate data are usually obtained in three ways :

1. Standard strand burners often called Crawford burner;

2. Small-scale ballistic evaluation RM;

3. Full-scale RM.

The burning rate measured on strand burner (small-scale RM) is usually lower than the obtained from real RM firing by $5-12 \%$ [2], since it does not truly simulate the hot chamber environment and scaling effects.

For the evaluation of RM performance parameters, the static firing test allows to measure the pressure and thrust histories. The measurement records are then analyzed to get detailed performance data.

In order to check the validity of the computer simulation software, the static firing test of the real RM (122mm diameter) is tested, the basic configuration is shown in Fig. (2), the measured data is analysed and compared to the results obtained from theoretical computation. Static firing test for real $122 \mathrm{~mm} \mathrm{RM}$ is performed in the Abou Zaabal Company test facility. Fig. (3) shows the corresponding records of pressure and thrust versus time as the main output results of real firing RM (shown by dash lines) and the theoretical results obtained from the simulation software (shown by continuous lines). It can be seen that the comparison showed good agreement, which proves the validity of the developed simulation model software by a maximum error less than $\approx 5 \%$.

\section{5: Theoretical Analysis}

Most CFD simulations performed for the space shuttle boosters and large SPRM [7]. In SPRM design and development, the use of the numerical model able to predict and simulate the behaviour of internal ballistics phenomena presents a valuable tool to predict the RM performance, with less number of firing, saving time, cost and risky tests.

The mathematical model is adapted to the computer program in FORTRAN language with SI units. It is capable of calculating the regression rates, pressures, velocities and SP grain 
Military Technical College

Kobry El-Kobbah,

Cairo, Egypt

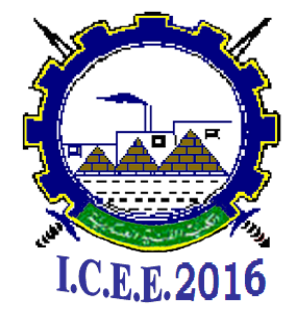

$8^{\text {th }}$ International Conference

on

Chemical \& Environmental

Engineering

$19-21$ April 2016

geometries in two sections, at the head and nozzle ends of the SP grain. The graphical representation of the results is given through Figs. (3-6).

The present analysis avoids the mentioned difficulties through the assumption that the surface regressions and pressures vary in a linear fashion along the length of SP grain. The burning rates and pressures are separately calculated at the head and nozzle ends of SP grain. Support for this assumption as a good approximation may be found in the results of interrupted burning tests $[2,4]$. The burning rate at the head end $r_{h}$ is computed using Eq. (1) while the burning rate at nozzle end $r_{n}$ is computed using Eq. (2) which takes the erosive burning into consideration during all burning time.

The chamber pressure and thrust versus time obtained from the computer program are plotted, Fig. (3), and compared with test results. It can be seen that theoretical predictions are in good agreement with the test results by error less than $5 \%$. This can be explained by the fact that grain regression in the ignition period is neglected, secondary, the effect of used assumptions during mathematical model and finally, the influence of assumed input data during theoretical work.

The SP grain internal burning occurs under the combustion gas pressure, the burning area and delta pressure variation during the firing time, the burning rates and combustion gas velocity profiles are shown in Figs. (4, 5 and 6) respectively.

After the ignition phase, it is noticed that the chamber pressure is increased significantly this due to effect of erosive burning phenomena, the internal burning to initial port area ratio is small $\left(\mathrm{A}_{\mathrm{po}} / \mathrm{A}_{\mathrm{th}} \approx 1.5\right)$, the burning and throat areas remain approximately constant for $0.5 \mathrm{sec}$ and the combustion gas velocity becomes large $\approx 500 \mathrm{~m} / \mathrm{s}$. The heat flux transferred to the burning surface increases the burning rate especially at the nozzle end section by twice value.

At the end of firing time, the SP port area increases $\left(\mathrm{A}_{\mathrm{po}} / \mathrm{A}_{\mathrm{th}} \approx 9.5\right)$, combustion gas velocity decreases less than $100 \mathrm{~m} / \mathrm{s}$ and post burning rate decreases until becoming equal the aft regression rate.

At middle of firing time $\approx 1.5 \mathrm{sec}$, the ratio $\mathrm{A}_{\mathrm{po}} / \mathrm{A}_{\mathrm{th}} \approx 5.5$, the burning surface increases during long time of firing and mass flow rate generated increases to make a slight compensation of combustion velocity decrease as shown in Figs. (5-6).

Figure (4) shows the variation of pressures along active channel of SP grain (at head $\mathrm{P}_{\mathrm{h}}$ and nozzle $\mathrm{P}_{\mathrm{n}}$ ends) with operating time. The general trend is described by strong regressive burning during the first $0.5 \mathrm{sec}$, then progressive burning up to $\approx 2.7 \mathrm{sec}$., which corresponds to the start of the tail-off phase.

The difference between $\mathrm{P}_{\mathrm{h}}$ and $\mathrm{P}_{\mathrm{n}}$ can be explained by the drop of pressure along the active channel port of burning SP grain, this difference is diminished with the burning time. This can be explained as the active channel port area is continuously increasing with decreasing combustion gas velocity as shown in Fig. (6), which means that the last term in Eq. (8) is reduced accordingly. The duration of the tail-off phase reflects the relative importance of the erosive burning effect. This effect is more pronounced with higher slenderness ratio of the SP grain. 
Military Technical College

Kobry El-Kobbah,

Cairo, Egypt

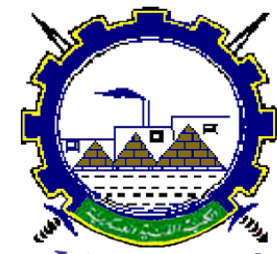

I.C.E.E.2016 $8^{\text {th }}$ International Conference

on

Chemical \& Environmental

Engineering

$19-21$ April 2016

Figure (6) shows the variation of the burning rates along SP grain versus time. The higher effect of erosive burning is clear at the beginning of firing of RM, mainly after ignition phase. By time, the difference between the two burning rates is diminished. This can be explained by the important increase in the SP port area which reduces the last term $\left(\dot{m}_{g e n} / A_{p o}\right)$ in Eq. (8).

The erosive burning exceeds the steady-state operation for a small interval of time immediately after the ignition phase. Figure (5) shows the burning surface of SP star grain configuration and the rate of change of pressure during different phases of RM operation. Unsteady phases at the first operating time due to higher rate of change of burning rate and also during tail-off phase due to higher change of burning surface.

\section{Evaluation of Erosive Burning}

One of the most difficult RM internal ballistic parameters to evaluate is the erosive burning of solid propellant. Yet, this parameter must be known throughout the firing duration to determine accurate propellant utilization. The erosive burning has a serious effect on the performance of SPRM as shown in Figs (7-9) and Table (1).

The erosive burning is affected with partial loss of nozzle throat material, chamber casing insulation specially close to the nozzle part and internal ballistic parameters specially the SP burning surface. The chamber pressure and thrust will increase by $50 \%$ at start of firing and diminishes to $18 \%$ after $1 \mathrm{sec}$ to $8 \%$ at the end of burning time, due to the additional mass flow generated from the erosive burning term as shown in Figs. (7-9) with 14\% decreases of burning time and tail-off phase.

The erosive ratio $\left(r_{n o z} / r_{0}\right)$ increases as the flow velocity increases the double. There exists a threshold velocity $\approx 180 \mathrm{~m} / \mathrm{s}$, mass flux $\approx 1.5 \mathrm{gm} / \mathrm{s} . \mathrm{mm}^{2}$, port to throat areas $\approx 4$ as shown in Figs. (10-11).

\section{Analysis and Discussion}

Extensive experimental and numerical modeling studies on SP (double and composite) have been represented by Razdan and Kuo [8].

SPRM performance is more sensitive to erosive an burning phenomenon, which is mainly caused by two dependent parameters, the SP combustion gas velocity called erosive burning based velocity and the upstream mass flow flux called erosive burning based mass flux.

There are two essential types of SP erosive burning based on the effect of main vital parameters as:

1. Erosive burning based combustion gas velocity $v_{\mathrm{g}}$,

2. Erosive burning based combustion gas generated mass flux $G_{g}$.

A considerable number of expressions for the erosive rate proposed by different authors are found in $[1,2,6]$. The SP erosive burning occurs at a certain location along the burnt surface during definite parameters for combustion gas velocity and mass flux. 
Military Technical College

Kobry El-Kobbah,

Cairo, Egypt

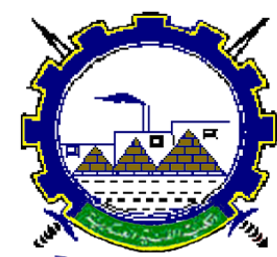

I.C.E.E.2016 $8^{\text {th }}$ International Conference

on

Chemical \& Environmental

Engineering

$19-21$ April 2016

As shown in Fig. (12), both the gas mass flux and velocity erosive burning are recommended erosive that can occur anywhere in the aft end of SP grain, it can be more simplified than Eq.

(2) as follows:

$$
r_{e}=0.00002\left(G_{g} V_{g}\right)^{0.891}(\mathrm{~mm}, \mathrm{gm}, \mathrm{s})
$$

Based on the data measured during real firing real scale RM and the analysis of theoretical work, the author noted and recommended the following:

- Erosive burning rate increases the generated combustion mass flow and thus also the chamber pressure and thrust during the early portion of burning.

- Erosive burning refers to the increase in the SP burning rate surface caused by the high velocity flow of combustion gases over the burning propellant surface. It can seriously affect the performance of SPRM, it occurs essentially in the active change post toward the nozzle.

- The max recommended erosive burning based on the port-to-throat area ratio is less than 4 , with threshold $\mathrm{G}_{\mathrm{tot}} \geq 1.5 \mathrm{gm} / \mathrm{s} . \mathrm{mm}^{2}$.

- As the SP port area increases with burning time, the erosive burning rate and combustion gas velocity tend to decrease until burning rates along active port surface are approximately the equivalents.

- Effect of erosive burning rate term can be neglected specially at upstream velocity $\leq$ $180 \mathrm{~m} / \mathrm{s}$, When the erosive ratio $\mathrm{r}_{\text {total }} / \mathrm{r}_{\mathrm{o}} \leq 1.1$.

- The high velocity of combustion gases near the burning surface and the turbulent flow inside boundary layer adjacent to burning surface increases the heat flux transferred to the SP surface and thus increases the burning rate.

- Regression rate also causes early burnout of the web, at the nozzle end; it exposes the more insulation layer thickness and more inert mass for aft closure to prevent local thermal failure.

- The variation of burning rates along SP grain leads to pressure differences that result an extra axial load and deformation of the grain, which must be considered in the stress analysis.

- Erosive burning increases the tail-off period, which increases the dispersion for artillery rockets.

- High erosive burning can affect the combustion instability because of increased heattransfer rate, gas velocity, higher pressure and burning rate drop along combustion channel.

\section{Conclusion}

A mathematical model is introduced and a computer program is built to describe the behavior of erosive burning for internal ballistic study. The numerical simulation model of erosive 
Military Technical College

Kobry El-Kobbah,

Cairo, Egypt

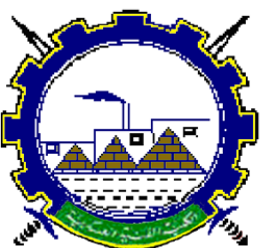

I.C.E.E.2016 $8^{\text {th }}$ International Conference

on

Chemical \& Environmental

Engineering

$19-21$ April 2016

burning during quasi state and tail-off phases based on Lenoir and Robillard formula are presented and validated.

The chamber pressure and thrust of an actual full scale motor are measured and compared with the theoretical data which include erosive burning model. The comparison between the results of both experimental and theoretical showed a very good agreement, with the maximum error less than $5 \%$ for performance parameters.

Unfortunately, with high value of the filling coefficient, the port area is decreased, leading to problems associated with erosive burning especially at the port to throat area ratio is equal 4 or less.

Erosive Burning is a very significant phenomenon, which occurs with most SP configurations. Erosive Burning generally occurs when high velocity combustion gases $\geq 180 \mathrm{~m} / \mathrm{sec}$. flowing over the SP burning surface is too fast, generally the surface at the end of grain. This often occurs with long and narrow effective channel port of SP grain compared with throat area $\leq 4$, since the higher propellant filling coefficient (volumetric loading) is the essential objective of designers especially in artillery rockets.

The simplified formula based on combustion gas velocity and generated mass flux is presented for the mainly effected parameters. Erosive burning as declared plays a dynamic role during firing operation, many parameters are observed for their effect on erosive burning behaviours. The RM designer must consider regression rate effect during design. Avoiding erosive burning is not a solution but evaluating the parameters is the proposed solution.

Table (1) Effect of calculated erosive burning on RM performance parameters

\begin{tabular}{l|c|c|c}
\hline Parameter & $\begin{array}{c}\text { With erosive } \\
\text { burning calculation }\end{array}$ & $\begin{array}{c}\text { Without erosive } \\
\text { burning calculation }\end{array}$ & Error\% \\
\hline \hline Initial chamber pressure, bar & 167.55 & 84.77 & -49.40 \\
\hline Min. chamber pressure, bar & 88.59 & 70.01 & -20.90 \\
\hline Max. chamber pressure, bar & 167.55 & 168.05 & +0.30 \\
\hline Average chamber pressure, bar & 128.07 & 119.03 & -7.10 \\
\hline Initial thrust, KN & 24.65 & 12.03 & -51.10 \\
\hline Min. thrust, KN & 10.51 & 13.61 & +29.49 \\
\hline Max. thrust, KN & 27.700 & 28.737 & +3.74 \\
\hline Average thrust, KN & 20.65 & 19.62 & -4.98 \\
\hline Average specific impulse, sec. & 244.99 & 252.19 & +2.94 \\
\hline Total impulse, KN sec. & 57.509 & 60.001 & +4.33 \\
\hline Active burning time, sec. & 3.333 & 3.398 & +1.95 \\
\hline Tail-off time, Sec. & 1.31 & 0.0 & --- \\
\hline Estimated RM weight, kg & 42.40 & 42.71 & +0.73 \\
\hline \hline
\end{tabular}


Military Technical College

Kobry El-Kobbah,

Cairo, Egypt

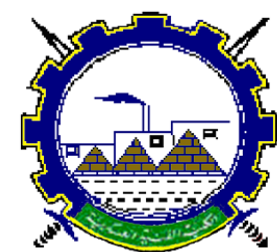

I.C.E.E.2016 $8^{\text {th }}$ International Conference

on

Chemical \& Environmental

Engineering

19-21 April 2016

\section{9: References}

[1] George P. Sutton “Rocket Propulsion Elements” Eighth Edition, John Wiley, ISBN 9780-470-08024-5, New York, 2010.

[2] Barrere, M. "Rocket Propulsion” Elsevier Publishing Company, 1960.

[3] Selph, C. "Computer Program For Calculation of Complex Chemical Equilibrium Composition” NASA SP-273, United States Air Force Academy, version, July 1994.

[4] Richard H. Sforzini "Design and Performance Analysis of Solid Propellant Rocket Motor" NASA contractor report, CR-129025, October 1972.

[5] Alain Divenas "Solid Rocket Propulsion Technology" ISBN 0-08-040999-7, Oxford, 1993.

[6] Kreidler J. W. "Erosive Burning: New Experimental Techniques and Method of Analysis" solid propellant rocket conference, California, 1964.

[7] Qunzhen W. "Development of Erosive Burning Models for Predictions of Solid Rocket Motor Internal Environments" AIAA-2003-4809, Alabama, July 20-23, 2003.

[8]Mukunda H. S. "Universal Behavior in Erosive of Solid Propellants" combustion and flame jornal - 109:224-236, 1997. 
Military Technical College Kobry El-Kobbah, Cairo, Egypt

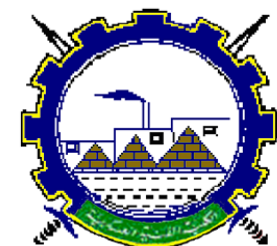

I.C.E.E.2016 $8^{\text {th }}$ International Conference

on

Chemical \& Environmental

Engineering

$19-21$ April 2016

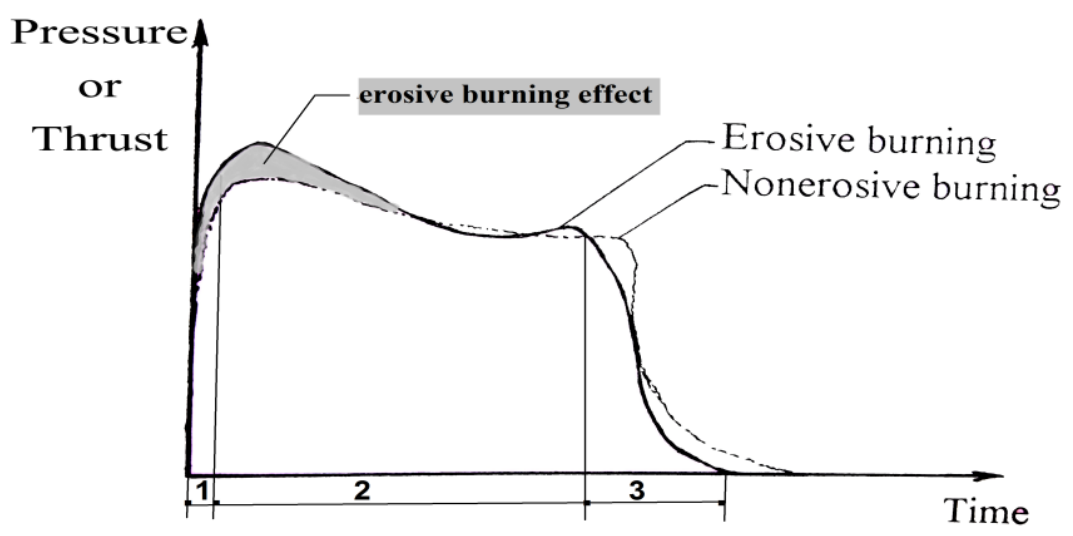

1 ignition phase, 2 steady state operation, 3 tail-off phase

Fig. 1 Erosive burning effects on pressure (thrust)-time profile
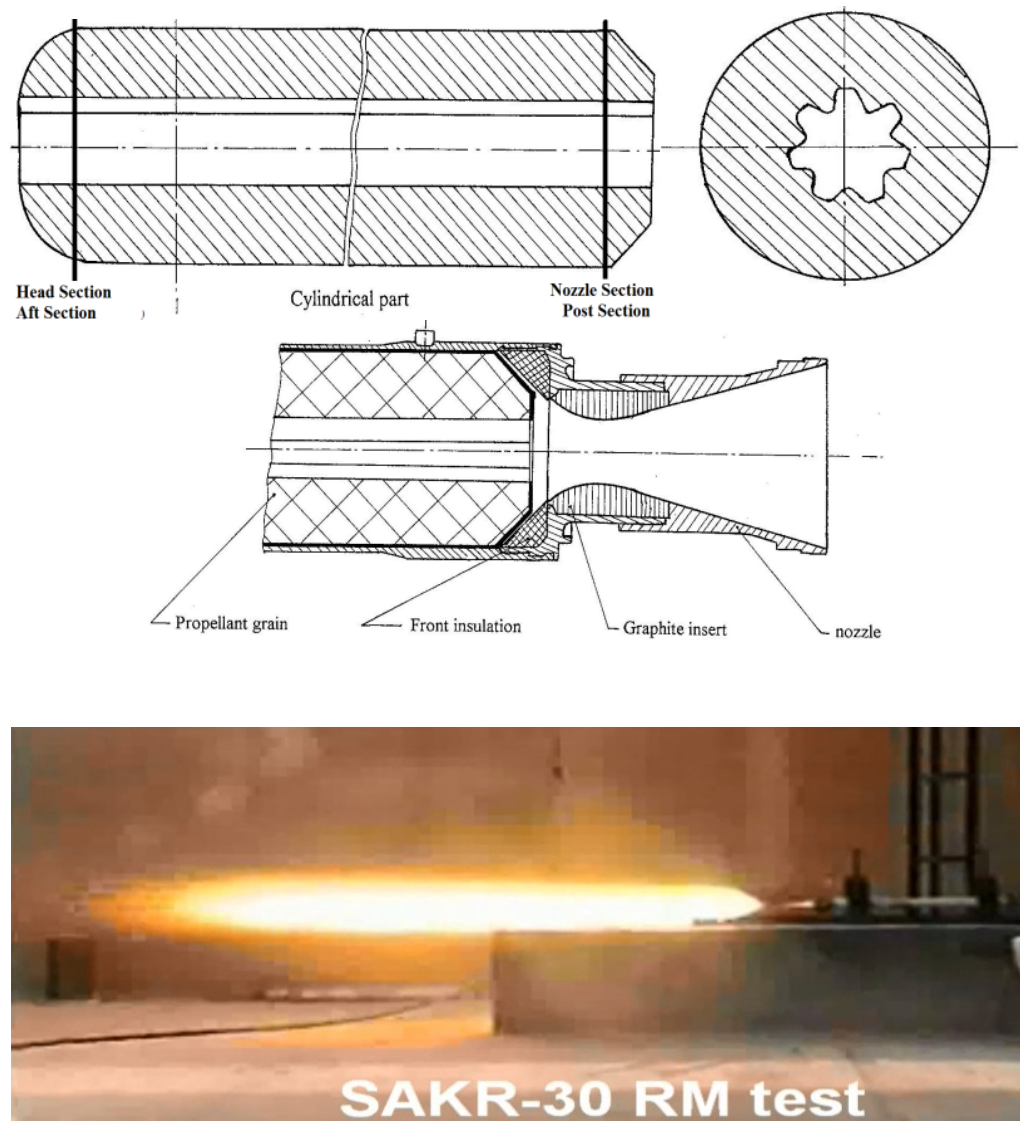

Fig. (2) Static firing test and a typical configuration of real $122 \mathrm{~mm}$ RM with composite SP grain 
Military Technical College Kobry El-Kobbah,

Cairo, Egypt

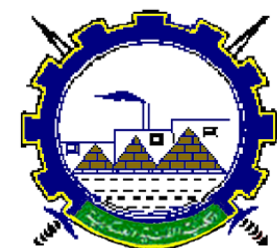

I.C.E.E.2016 $8^{\text {th }}$ International Conference on

Chemical \& Environmental Engineering $19-21$ April 2016

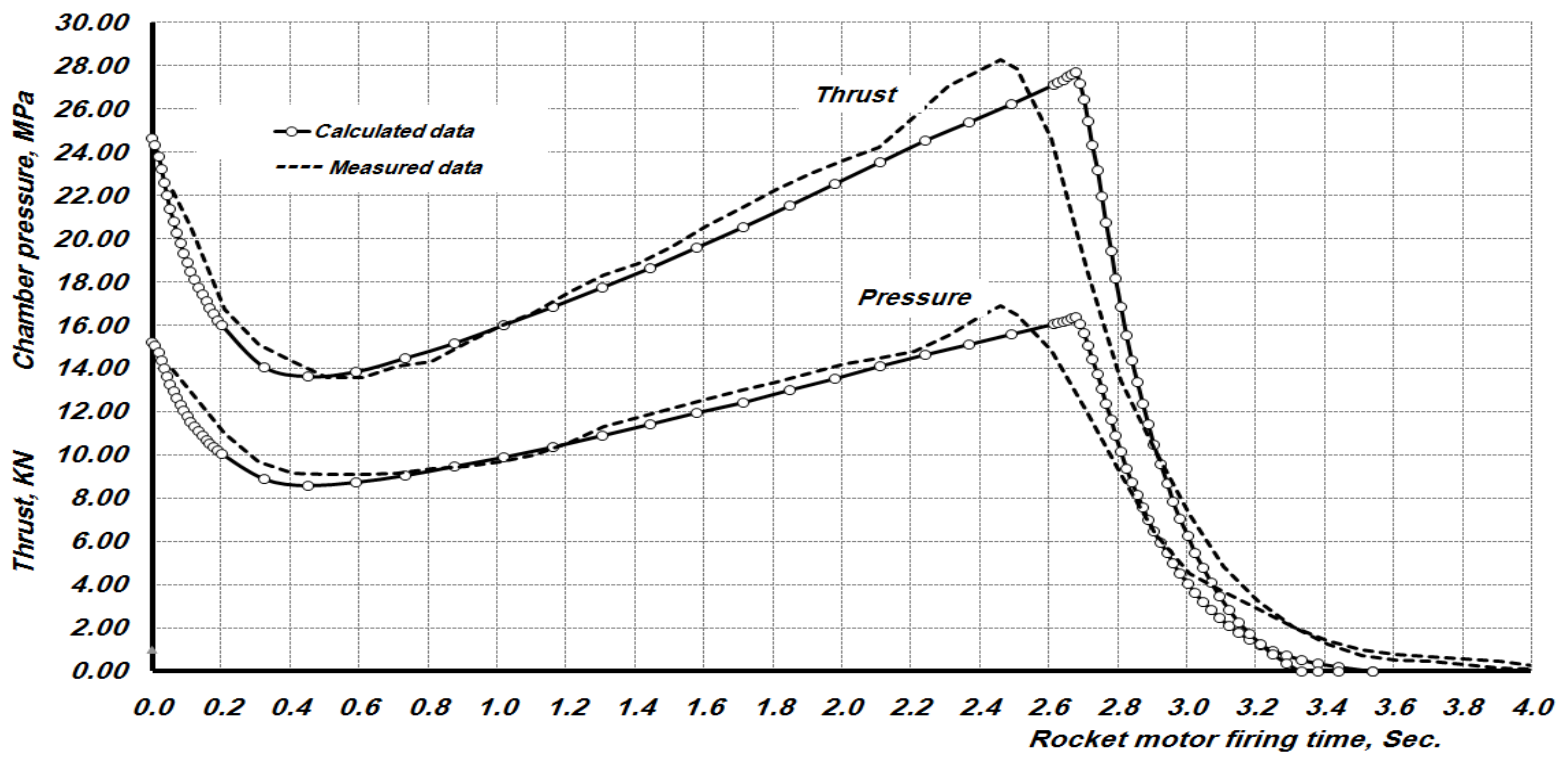

Fig. (3) Measured and calculated thrust and pressures for the tested $122 \mathrm{~mm}$ RM

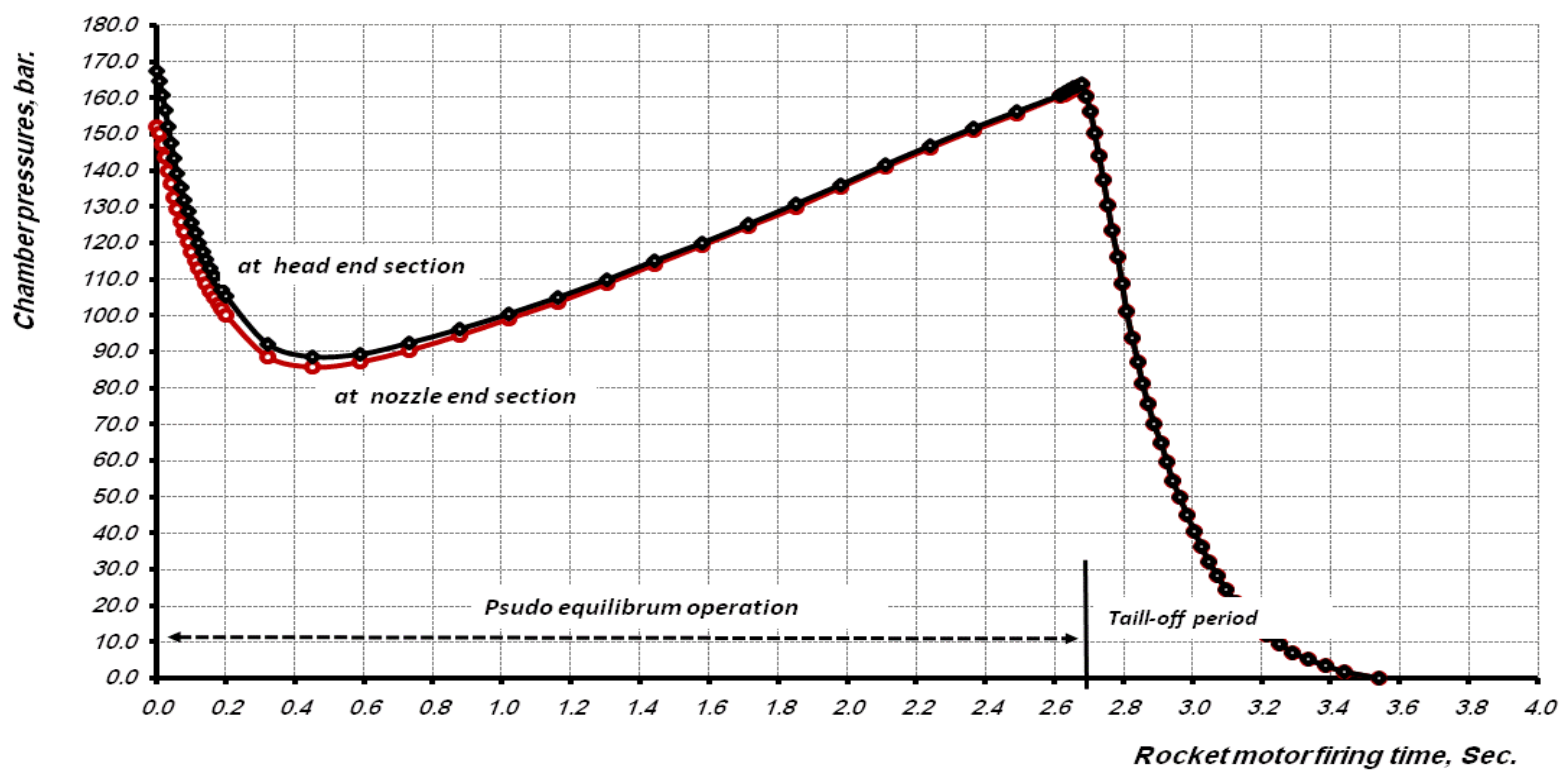

Fig. (4) Calculated head and nozzle end pressures versus firing time 
Military Technical College Kobry El-Kobbah,

Cairo, Egypt

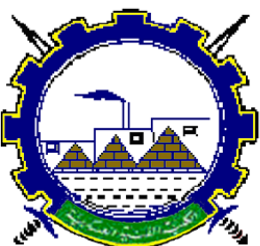

I.C.E.E.2016 $8^{\text {th }}$ International Conference

on

Chemical \& Environmental

Engineering

19 - 21 April 2016

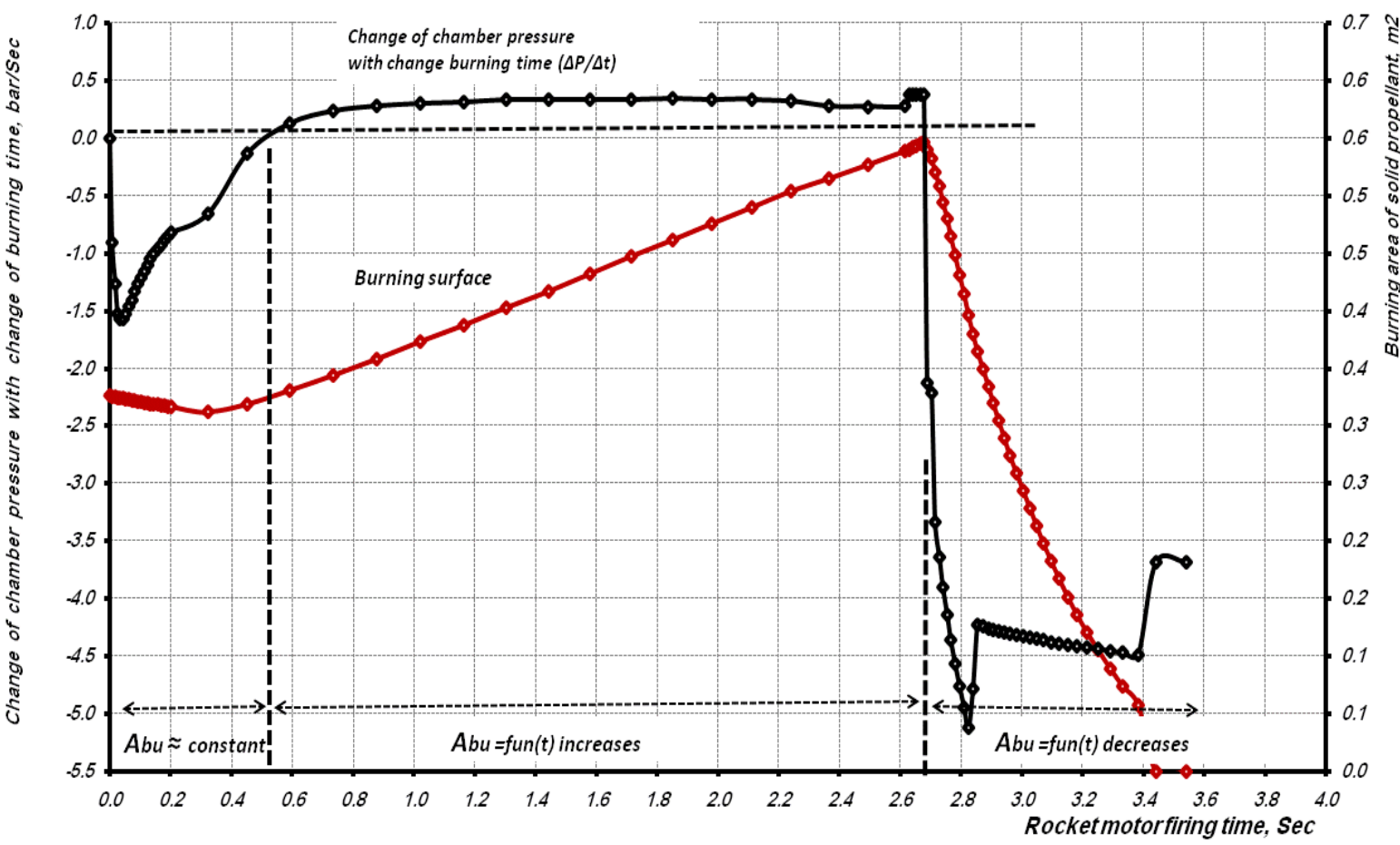

Fig. (5) Calculated burning surface and rate of chamber pressure change versus firing time

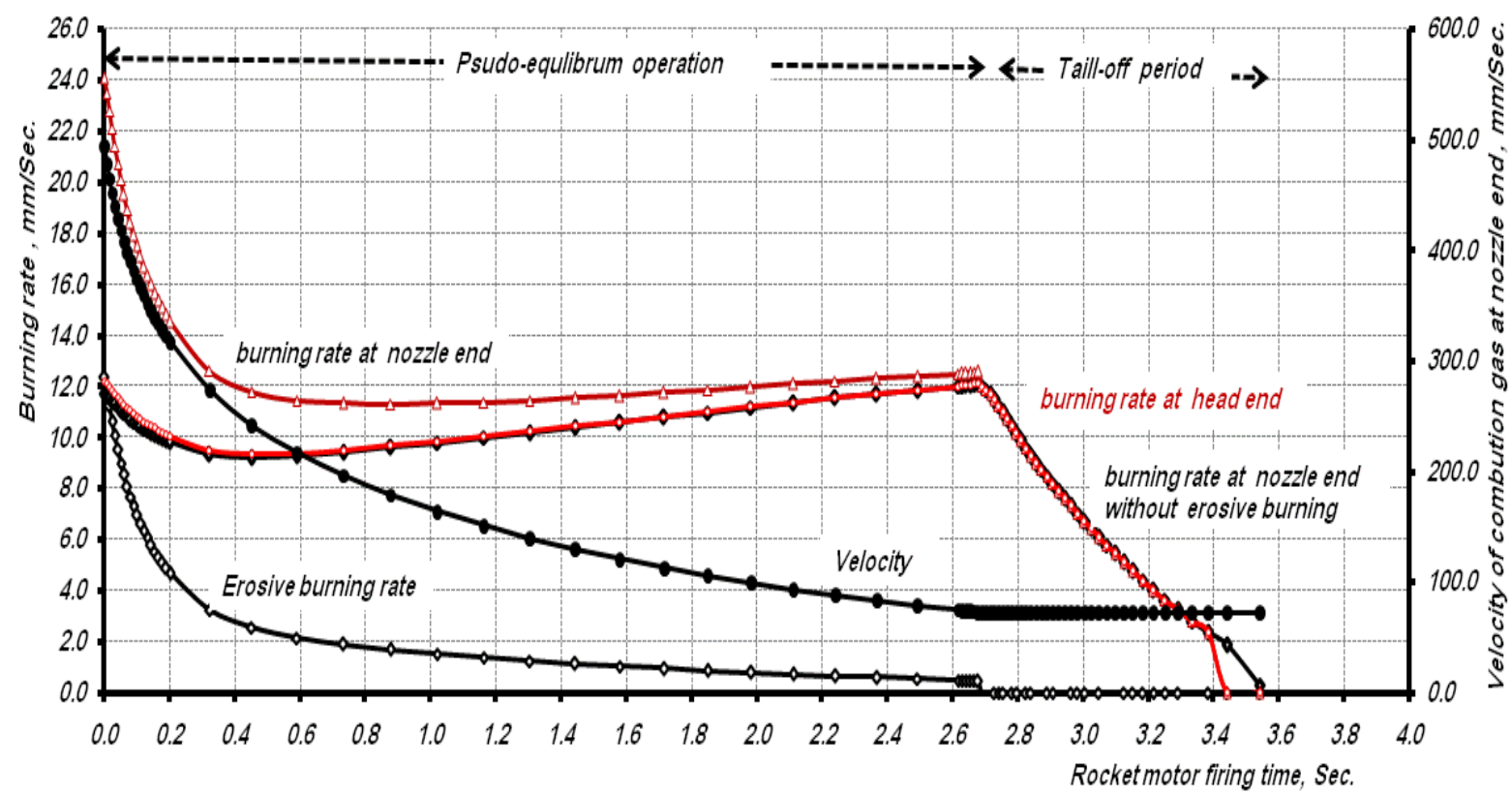

Fig. (6) Calculated burning rates and combustion gas velocity versus firing time 
Military Technical College

Kobry El-Kobbah,

Cairo, Egypt

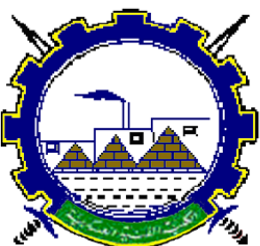

I.C.E.E.2016 $8^{\text {th }}$ International Conference

on

Chemical \& Environmental

Engineering

$19-21$ April 2016

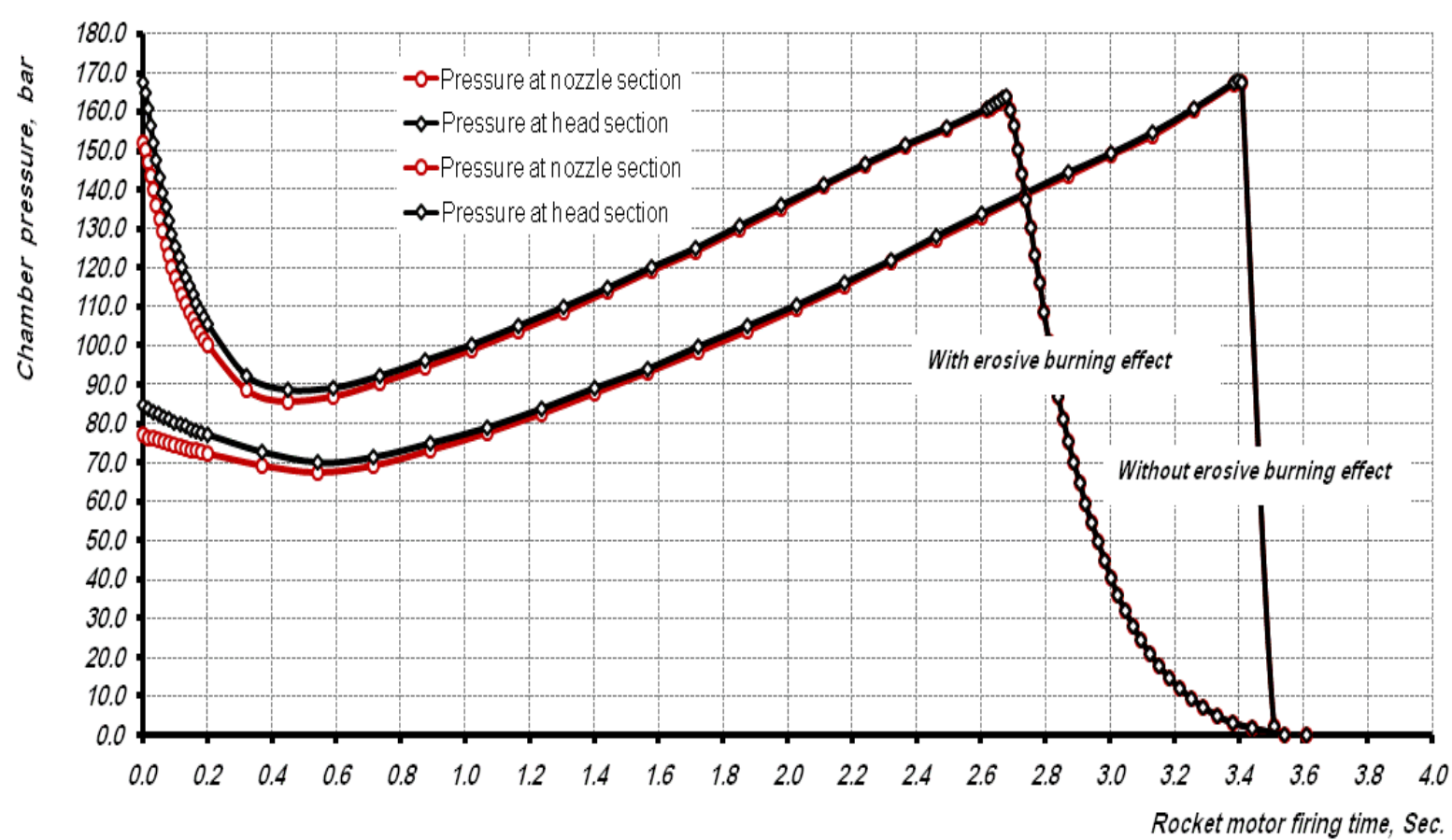

Fig. (7) Calculated chamber pressures versus firing time with and without erosive burning effect

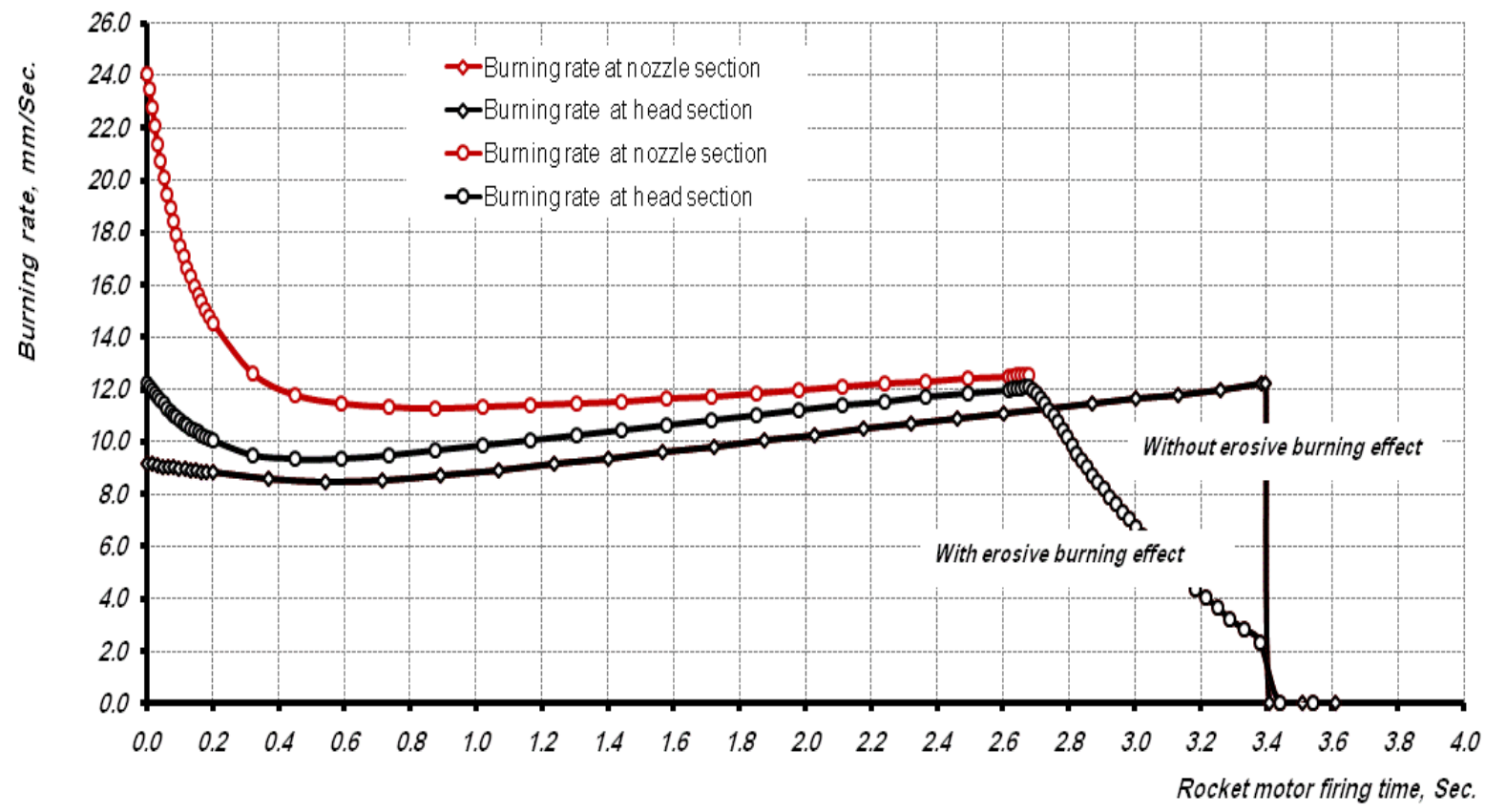

Fig. (8) Calculated burning rates versus firing time with and without erosive burning effect 
Military Technical College

Kobry El-Kobbah,

Cairo, Egypt

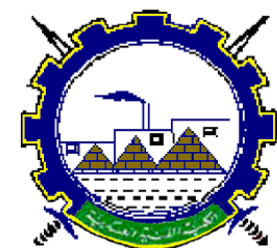

I.C.E.E.2016 $8^{\text {th }}$ International Conference

on

Chemical \& Environmental

Engineering

$19-21$ April 2016

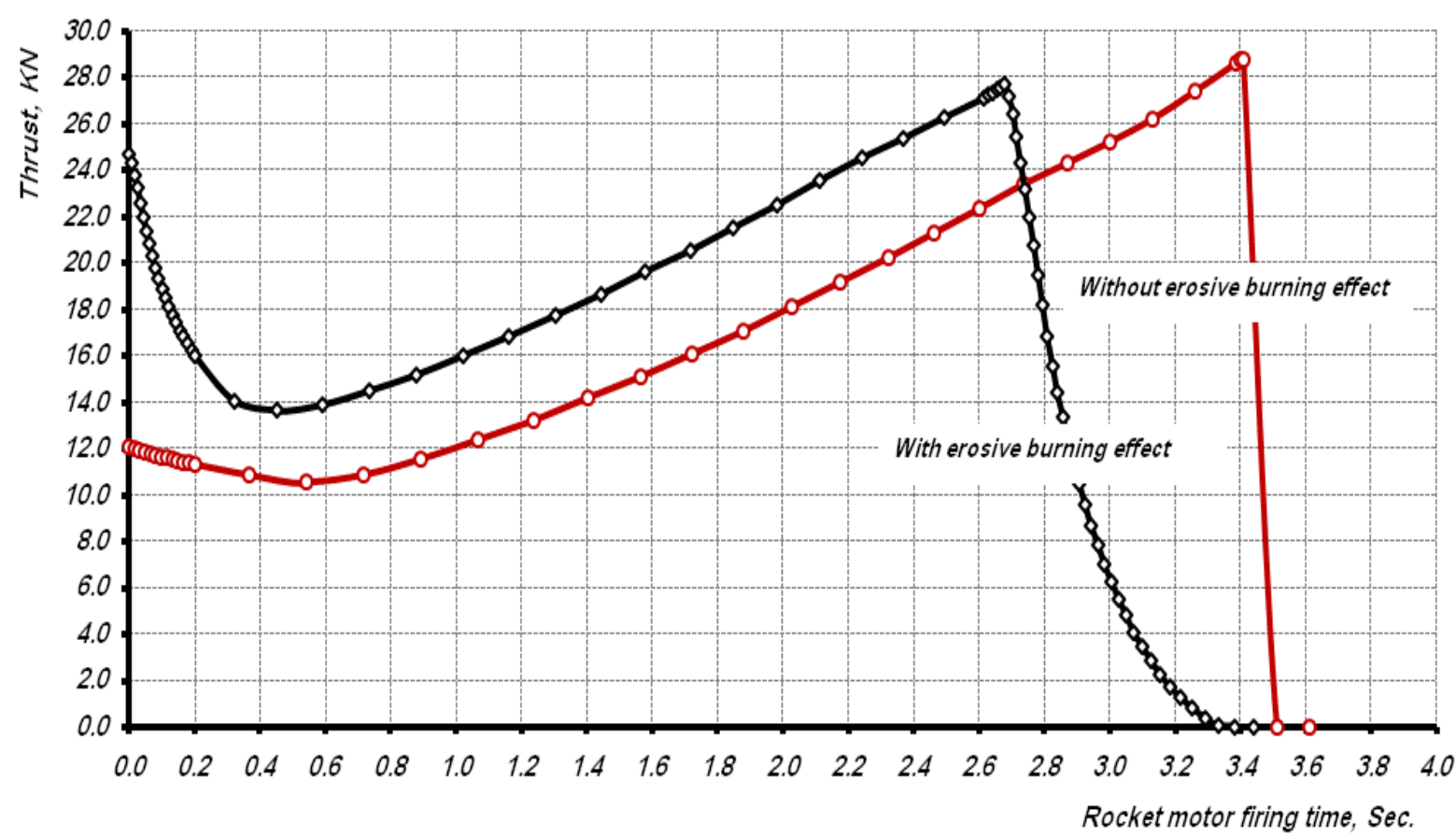

Fig. (9) Calculated thrust change versus firing time with and without erosive burning effect

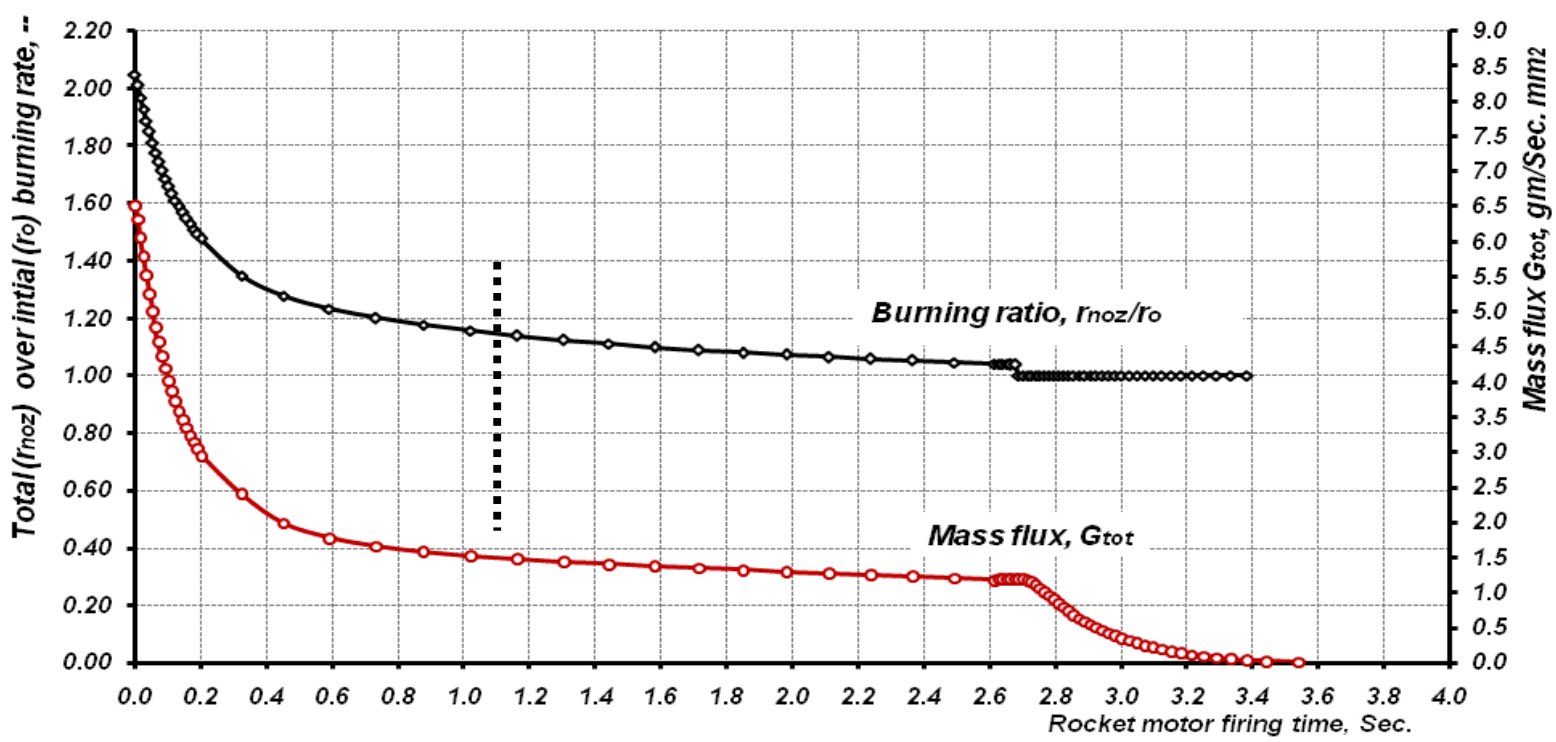

Fig. (10) Calculated burning rate ratio and mass flux change versus firing time 
Military Technical College Kobry El-Kobbah,

Cairo, Egypt

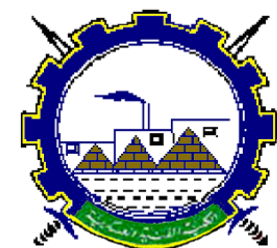

I.C.E.E.2016 $8^{\text {th }}$ International Conference

on

Chemical \& Environmental

Engineering

$19-21$ April 2016

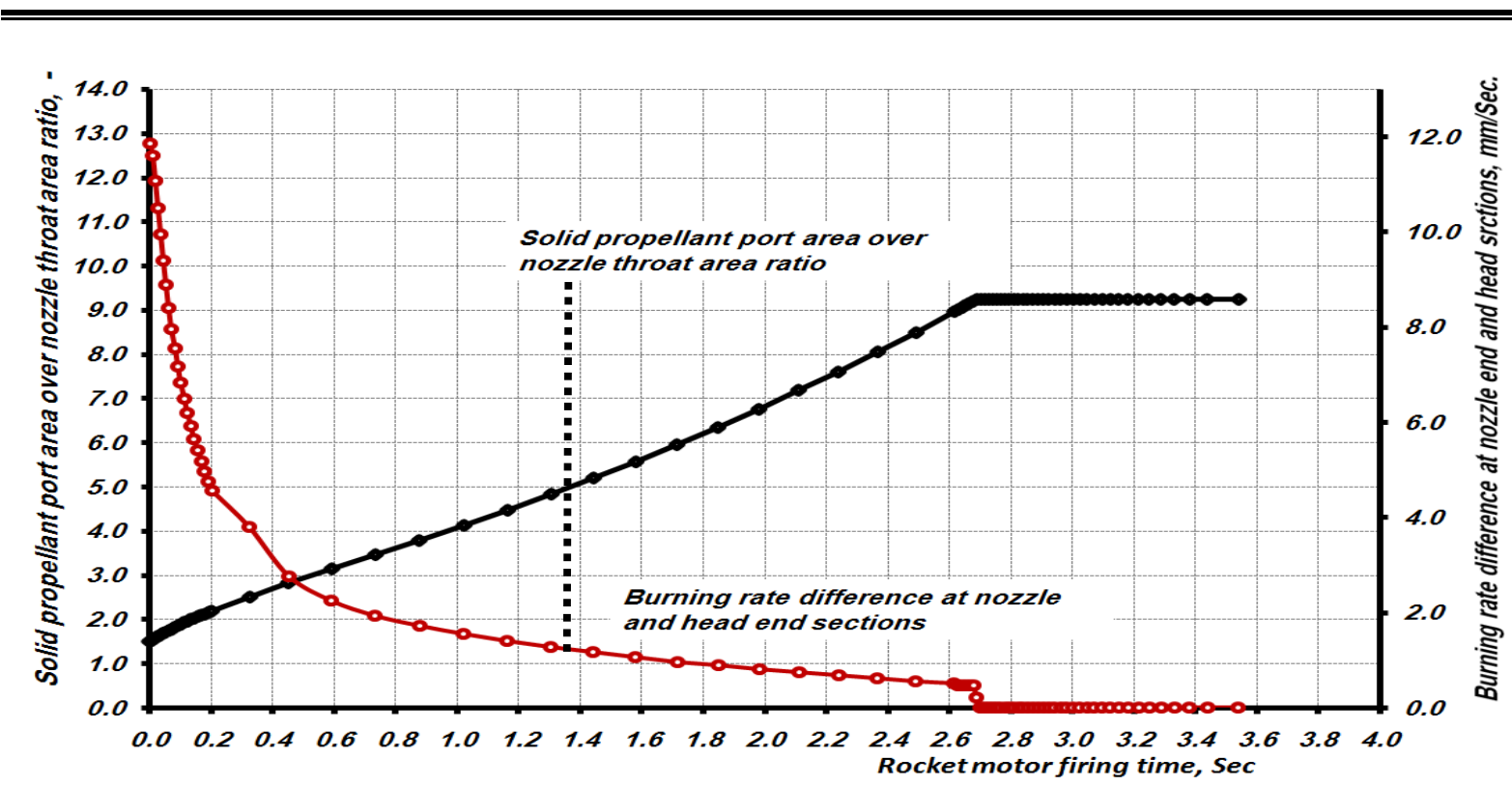

Fig. (11) Calculated burning rates difference and nozzle end gas velocity versus firing time

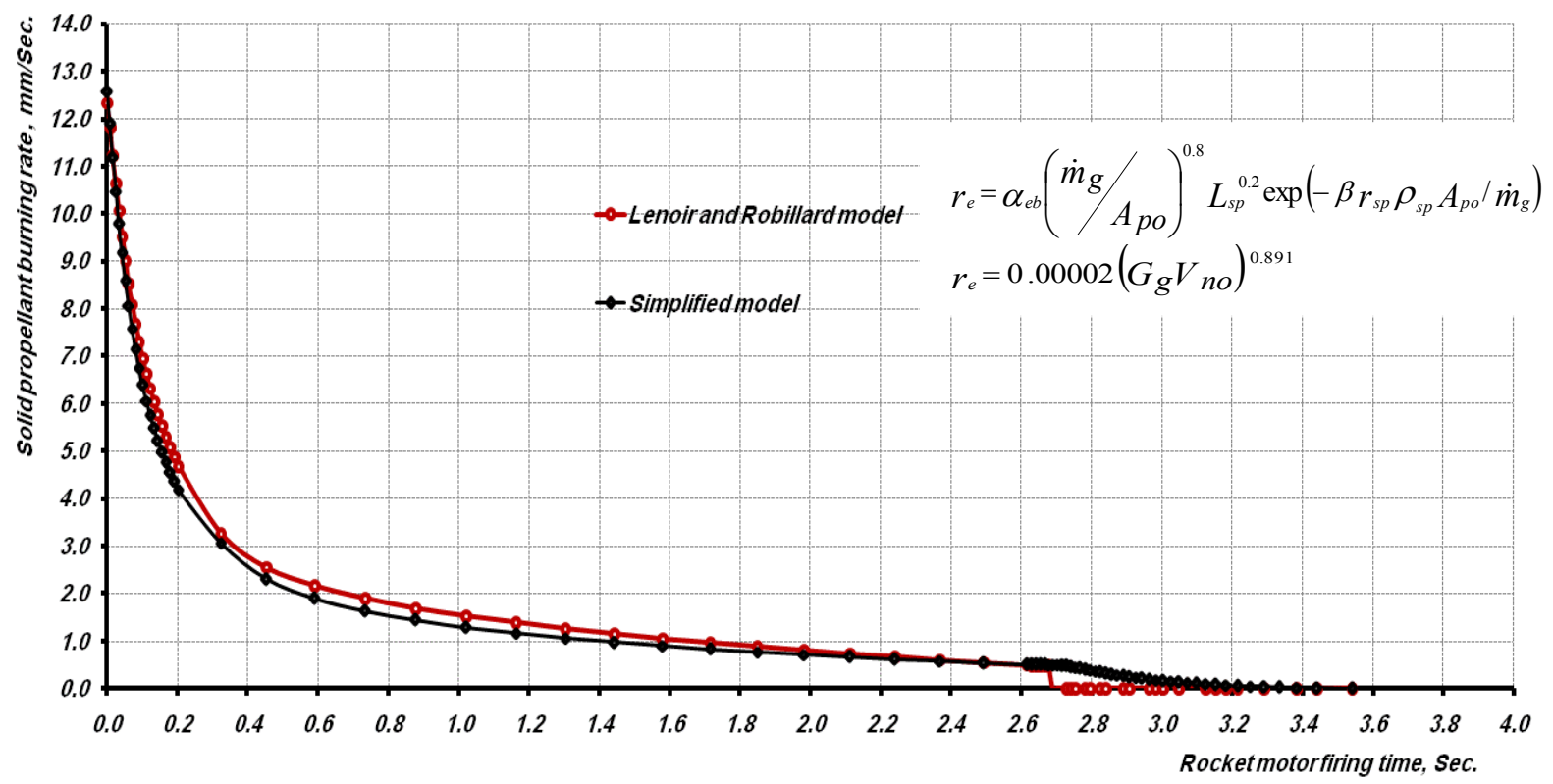

Fig. (12) Calculated L-R regression rate model and simplified model versus firing time 